\title{
Aging and the immune response to organ transplantation
}

\author{
Monica M. Colvin, ${ }^{1}$ Candice A. Smith, ${ }^{1}$ Stefan G. Tullius, ${ }^{2}$ and Daniel R. Goldstein ${ }^{1,3}$ \\ 'Division of Cardiology, Department of Internal Medicine, University of Michigan, Ann Arbor, Michigan, USA. 'Brigham and Women's Hospital, Harvard Medical School, Boston, Massachusetts, USA \\ ${ }^{3}$ Institute of Gerontology, University of Michigan, Ann Arbor, Michigan, USA.
}

\begin{abstract}
An increasing number of older people receive organ transplants for various end-stage conditions. Although organ transplantation is an effective therapy for older patients (i.e., older than 65 years of age), such as in end-stage renal disease, this therapy has not been optimized for older patients because of our lack of understanding of the effect of aging and the immune response to organ transplantation. Here, we provide an overview of the impact of aging on both the allograft and the recipient and its effect on the immune response to organ transplantation. We describe what has been determined to date, discuss existing gaps in our knowledge, and make suggestions on necessary future studies to optimize organ transplantation for older people.
\end{abstract}

\section{Introduction}

The number of people over 65 years of age seeking and receiving organ transplants is growing. Presently, the average age of those receiving kidney transplants is approximately 50 years (1). A similar trend is observed with other organ transplants: approximately $50 \%$ of patients who received cardiac transplants between 2002 and 2010 were over 50 years of age, and over $20 \%$ were older than 60 years (2). Along these lines, clinical studies have demonstrated that solid-organ transplantation is an effective treatment for selected older patients (3-8). However, older transplant recipients succumb to more infections and are more susceptible to post-transplant malignancies $(9,10)$. Most clinical studies in solid-organ transplantation (including heart, kidney, and lung) indicate that increased recipient age (age range, 50 to $>70$ years) is associated with a reduced frequency of acute allograft rejection $(6,10-13)$, although acute graft rejection in older transplant recipients may be more severe than in younger recipients $(3,14)$. Despite a growing body of evidence on the complex effects of immunosenescence $(15,16)$, there have been relatively few studies that have focused on aging and the immune response to organ transplantation. In addition, most therapeutic trials in organ transplantation have not included patients over 65 years of age.

Besides the impact on the recipient's immune response, aging also affects the donor organ before transplantation (17). Older organs can exhibit more pronounced immunogenicity, respond differently to stress, and repair less well than younger organs subsequently to transplantation $(17,18)$. These limits are due to the deleterious effects of aging on organ function, the vasculature, and alterations of resident immune cells, all of which limit the expansion of the donor pool for patients awaiting organ transplantation.

Here, we describe how aging alters the immune response to organ transplantation in both the allograft and the recipient.

Conflict of interest: The authors have declared that no conflict of interest exists. Reference information: J Clin Invest. 2017;127(7):2523-2529. https://doi.org/10.1172/JCI90601.
Although biological aging represents a spectrum and clinical studies define age differently, we characterize older individuals as those greater than 65 years of age, unless stated otherwise.

\section{Impact of aging on the donor}

Clinical impact. Advanced donor age has historically been associated with poor outcomes after transplantation, although the impact of donor age can vary by organ $(19,20)$. In heart and kidney transplants, increased donor age is a risk factor for mortality and delayed graft function (21). Donor age affects both quality and longevity, and its effect on patient survival in kidney transplantation has been shown to be greater than that of the histocompatibility difference between donor and recipient (22). Kidneys from donors $\geq 55$ years of age have lower glomerular filtration rates and fewer functioning glomeruli than those from donors $\leq 45$ years, which may contribute to decreased longevity seen in older kidneys (23). Donor hearts greater than 40 years of age are four times more likely to have chronotropic incompetence requiring permanent pacer implantation, and donors older than 50 years are more likely to be CMV seropositive, all of which may impact post-transplant graft function and longevity $(24,25)$. Use of lungs from donors greater than 60 years of age leads to acceptable outcomes, but there is a trend toward shorter survival at 10 years after transplant in older recipients compared with younger recipients (26). The Eurotransplant Senior Program was developed to optimize use of organs and decrease waiting time by age-matching kidneys $(27,28)$. Based on this study, age-matching of organs is associated with less optimal but acceptable short-term and long-term outcomes. Interestingly, and in support of "immunological matching" between donor and recipients, rejection rates of older organs are lower when transplanted into older recipients than younger ones (29).

Ischemia/reperfusion injury and resulting inflammation. Ischemia/ reperfusion injury (IRI) is a process that is initiated during hypotension or circulatory arrest if organs are procured from donation-aftercardiac-death donors or brain-dead donors. Importantly, subsequently to reperfusion, IRI activates the recipient's innate immune system and, in turn, primes the recipient's adaptive immune system, 
which increases antidonor immunity (30). The cell necrosis that occurs during IRI leads to the release of intracellular contents (e.g., mitochondrial DNA) or components of the basement membrane (e.g., hyaluronan), which activate the innate immune system within the allograft (31). Several innate immune pathways have been implicated in IRI after organ transplantation, for which Toll-like receptor (TLR) pathways are particularly important $(31,32)$. Specific gene knockout studies (e.g., TLR2 or TLR4 or in the TLR signal adaptor protein MyD88) have demonstrated an abrogation of IRI in models of cardiac and kidney organ transplantation (33). Moreover, deletions of MyD88 in donor animals or the graft have been shown to reduce alloimmunity (34). These studies demonstrate that TLR signaling via MyD88 is a central pathway controlling innate and subsequent adaptive alloimmunity (35).

Aging may influence the consequences of IRI by affecting the initial inflammatory response within the graft. Aging has complex effects on the innate immune system (36), and most of its impact is focused on immune cells such as DCs and macrophages (36). Generally, innate immunity declines with aging (36), but a lowgrade elevated inflammatory phenotype consisting of the release of inflammatory cytokines (e.g., IL-6 and TNF- $\alpha$ ) has been associated with aging $(37,38)$. The source of the inflammatory cytokines with aging remains unclear, but possibilities include the adipose tissue and the vasculature (39). For example, old aortas from mice aged 18-20 months exhibit a "proatherogenic" phenotype under basal conditions with a higher secretion of the monocyte-attracting chemokine CCL2 and the proinflammatory cytokine IL- 6 than in young mice (2-3 months of age) (40). The mechanism responsible for the IL-6 response of aging aortas (40) has been shown to be the activation of MyD88 within vascular smooth muscle cells.

In organ transplantation, innate immune activation within an allograft may be mediated via the vasculature, cardiomyocytes (in the case of heart transplantation) or other stromal cells, or passenger immune cells. Yet no experimental studies have determined the impact of aging on any of these compartments during IRI. Thus, future research will be needed to determine whether altered innate immunity with aging within an allograft impacts IRI and subsequent antidonor immunity.

Aging may also affect the capacity of an organ to respond to repair mechanisms based on altered metabolic, bioenergetic, and functional reserves within an older organ. Experimental studies in ex vivo-perfused rat cardiomyocytes, for example, have demonstrated that aging is linked to augmented damage during hypoxia leading to impaired oxidative phosphorylation, increased ROS, and defective mitochondrial function (17, 41). Silent mating type information regulation 2 homolog 1 (SIRT1) is a member of the sirtuin family of proteins and is a $\mathrm{NAD}^{+}$-dependent protein deacetylase that has a broad impact on gene transcription (42). A general decline in SIRT1 activity with aging may also contribute to compromised myocardial repair $(43,44)$. Aging also leads to a decline in other protective cellular mechanisms. For example, impaired liver IRI with aging has been associated with a reduction in the cytoprotective chaperone HSP-70 (45). Thus, it appears that an aging allograft exhibits fewer protective mechanisms capable of enduring any extremes of IRI.

Effect of donor allograft age on recipient's alloimmune responses. Increasing donor age, independent of recipient age, increases the rate of acute allograft rejection (29). This finding is also supported by an experimental study in which, after implantation into young recipients, older murine cardiac allografts (donors 18 months of age) underwent a faster tempo (1-5 days faster vs. young allografts) and more severe acute allograft rejection than allografts from young donors (donors 2 months of age) (18). By deletion of immune cells in the donor either via lethal irradiation or via pharmacological approaches (i.e., clodronate treatment), donor DCs were implicated in the accelerated tempo of graft rejection with aging in the same study (18). Moreover, DCs from the spleens of old donor mice exhibited increased expression of costimulatory molecules (e.g., CD80, CD86, and CD40) and an enhanced ability to induce antidonor $\mathrm{T}$ cell responses in vitro (18). These findings were consistent with a prior study that found that aged DCs induced higher levels of graft-versus-host disease than young DCs $(46,47)$, although direct examination of DCs from aged cardiac allografts was not performed in the former study (18). Assessing tissue-resident immune cells is important for understanding how aging impacts immune responses within organs, as there is an increasing appreciation of the contribution of these cells in maintaining organ homeostasis $(18,48,49)$. Finally, targeting IL-17 - a cytokine that contributes to Th cytokine responses, especially chronic rejection after organ transplantation $(50,51)$ - in recipient mice either genetically or via antibody depletion also prolongs the survival of older grafts (18).

The above study examining the age of cardiac allografts partly contrasts with an earlier experimental murine skin allograft study, in which older skin grafts (donor age of 18-22 months) were rejected at a similar tempo to that of young skin allografts (donor age of 2-4 months) (52). Furthermore, DCs purified from the spleens or propagated from the bone marrow of aged mice did not enhance $\mathrm{T}$ cell alloimmunity in contrast to DCs from young mice (52). Differences between the two studies could be due to the experimental transplant models used (heart vs. skin), the age of the mice (18 months vs. 18-22 months), or unknown factors within the environment in which the mice were maintained. Despite the differences between these two studies, it is likely that aging exerts important effects on passenger immune cells or stromal cells within a donor allograft. What is not known is whether, in contrast to young allografts, aged allografts have an altered ability to induce infiltration of immune cells into allografts as compared with young allografts. Furthermore, comparison of different organs (e.g., lungs, kidneys, and heart) could inform as to whether aging is tissue-specific in the donor.

Donor age and chronic allograft injury. Clinical studies have established that the age of the allograft is a strong independent predictor for the development of chronic allograft vasculopathy (53-55) and the largest single contributor to chronic graft loss (56). Based on this knowledge, most centers in the US limit acceptance of donor organs. For example, heart allografts are generally not accepted from donors older than 60 years. Despite this established clinical phenotype, there is little experimental evidence that provides mechanistic insights into how aging within the donor enhances the development of allograft vasculopathy. A prior study in a rat kidney allograft model found that donor age (up to 18 months) synergized with donor ischemia time (up to 120 minutes) in impairing allograft function (defined as creatinine clearance and proteinuria) (57). However, other components of the allograft have not yet been examined as contributors of increased vascu- 
lopathy within the aging allograft. Clearly, aging enhances the development of atherosclerosis (15), and atherosclerosis within an allograft is frequently a reason for not accepting an organ for transplantation. Moreover, even before the histological evidence of atherosclerosis, the vasculature exhibits low-grade increased inflammatory responses with aging $(40,58,59)$. These changes include the production of monocyte- and T cell-attracting chemokines in the aging vasculature (e.g., CCL2 and osteopontin) that enhance monocyte chemotaxis (15). Hence, these alterations within the vasculature could increase $\mathrm{T}$ cell and monocyte recruitment into the vasculature of an older allograft to increase transplant vasculopathy. Determining the mechanistic basis for enhanced vascular inflammation may pave the way for novel therapeutic strategies that could be applied to the graft before implantation to reduce the immunogenicity of older organs while preventing the development of allograft vasculopathy after implantation.

\section{The impact of aging on the adaptive T cell immune system}

Clinical studies show that aging affects various components of the immune response, which can lead to impaired host defense against tumors and infections as well as to defective vaccine responses and increased autoimmunity $(60,61)$. Most studies have focused on adaptive immunity - in particular, $\mathrm{T}$ cell function - with several reports showing that aging impairs T cell IL-2 production and Th1 immunity (62-64), CD28 signaling (65), and immune synapse formation (66). Furthermore, aging reduces $\mathrm{T}$ cell thymic output as a result of thymic involution, leading to reduced numbers of naive T cells and Tregs. Aging also leads to an accumulation of memory $\mathrm{T}$ cells within the lymphoid system (61). The above alterations reduce the size of the naive $\mathrm{T}$ cell receptor repertoire, leading to oligoclonality of the naive $\mathrm{T}$ cell pool (13). In vitro experiments performed both in humans and in mice indicate that $\mathrm{CD} 4{ }^{+} \mathrm{CD} 25^{+}$Treg function is not altered with aging (67, 68). Three prior studies documented that aging is associated with increased numbers of splenic and peripheral blood $\mathrm{CD} 4^{+} \mathrm{CD} 25^{+}$ Tregs (67-69), and one report indicates that inhibition of these cells restores antitumor immunity in aged mice (69).

Immune memory is a host defense mechanism that prevents reinfection and is the basis of vaccination therapies. Two studies in nontransplant models showed that aging leads to defective $\mathrm{CD}^{+}$and $\mathrm{CD}^{+}$memory $\mathrm{T}$ cell function $(70,71)$. A recent study described the presence of a novel lineage of memory $\mathrm{CD}^{+} \mathrm{T}$ cells that exhibit a naive $\mathrm{T}$ cell phenotype as well as enhanced IFN- $\gamma$ production with aging (72). These $\mathrm{CD}^{+} \mathrm{T}$ cells may play an important role in host defense against certain viral infections such as West Nile, which are more prevalent in older people (72).

\section{Effects of aging on the recipient immune response to organ transplantation}

Clinical impact of recipient age. Regardless of the type of organ transplant, recipient age has a substantial impact on the outcome of organ transplantation. In addition to the complex changes occurring within the immune system, there are also increasing comorbidities with aging. Thus, the aging recipient is subject to the complex interaction of the senescent immune system, immunosuppression, and comorbid conditions. In all solid-organ transplants, older recipient age is an independent risk factor for post-transplant mortality. Aging increases the risk of malignancy substantially in patients with solid-organ transplants, including non-Hodgkin's lymphoma, lung, liver, and kidney cancer (73). In addition to malignancies, infections also become more prevalent with increasing age (74). These effects may be due to the synergistic effects of immune senescence and medical immune suppression (75). Increasing recipient age is also associated with a decreased risk of rejection, although deaths related to rejection are more common in older adults (28). Chronic graft dysfunction is also more prevalent in older adults, a condition that results not only from immunological factors but also from comorbid conditions, such as hypertension and diabetes, which increase with aging (28).

$T$ cell responses. Of the few studies examining the impact of aging on the immune response to organ transplantation, most have focused on $\mathrm{T}$ cells. In one study, aged recipient mice (18-23 months of age) accumulated memory $\mathrm{CD} 44^{\mathrm{hi}} \mathrm{CD} 62^{\mathrm{lo}} \mathrm{CD} 4{ }^{+} \mathrm{T}$ cells and exhibited lower antidonor Th1 (i.e., IFN- $\gamma$ ) responses than young (2-4 months of age) recipients (76). This reduction was associated with a delay in the tempo of fully MHC-mismatched skin allograft rejection in aged versus young transplant recipients (76). However, memory $\mathrm{CD} 4^{+} \mathrm{T}$ cells from aged recipients exhibited elevated IL-17 antidonor T cell responses. In addition, an anti-IL-17 mAb delayed the tempo of skin allograft rejection in aged, but not young, recipients (76). The accumulation of memory $\mathrm{CD}^{+} \mathrm{T}$ cells, delayed skin allograft rejection, and reduced Th1 antidonor immune responses were largely confirmed in a later study (77), which also found that Treg suppressive function was preserved in aged mice (77).

Before transplantation, aged mice exhibit a reduced number of naive $\mathrm{CD} 8^{+} \mathrm{T}$ cells with similar numbers of effector and central memory $\mathrm{T}$ cells in the spleen (78), although the total numbers of memory $\mathrm{CD}^{+} \mathrm{T}$ cells are increased in aged mice $(18$ months of age) before transplantation $(79,80)$. Aged mice (14-18 months) resist the skin allograft-promoting properties of anti-CD45Rb and anti-CD154, which robustly enhance fully MHC-mismatched skin allografts in young murine recipients $(78,80)$. Depletion of $\mathrm{CD}^{+}$ $\mathrm{T}$ cells via an anti-CD8 mAb administered to aged skin allograft recipients treated with anti-CD 45Rb and anti-CD 45 substantially enhanced allograft survival (>30 days), whereas it had no effect in young skin recipients (78). CD8 ${ }^{+} \mathrm{T}$ cells were implicated in another experimental skin allograft study in which $\mathrm{CD}^{+} \mathrm{T}$ cells isolated from mice aged 18 months induced a substantially (>20 days) slower tempo of skin allograft rejection after adoptive transfer into lymphodeficient hosts than $\mathrm{CD}^{+} \mathrm{T}$ cells isolated from young mice (79). Interestingly, in this study reduced expression of CCL3 and $\mathrm{CD} 4 \mathrm{OL}$ on aged $\mathrm{CD} 8^{+} \mathrm{T}$ cells was associated with reduced $\mathrm{CD} 8^{+}$ $\mathrm{T}$ cell/DC interaction, indicating that alterations in aged $\mathrm{CD} 8^{+} \mathrm{T}$ cells may have important indirect effects on DC function.

Viral reactive memory $\mathrm{CD} 8^{+} \mathrm{T}$ cells develop the ability to cross-react with alloantigens, a phenomenon known as heterologous immunity (81). Heterologous memory CD8 ${ }^{+} \mathrm{T}$ cells have been shown experimentally to pose a barrier to the development of transplantation tolerance (81). Surprisingly, an in vitro study indicated that flow cytometrically purified naive $\left(\mathrm{CD} 62 \mathrm{~L}^{\mathrm{hi}} \mathrm{CD} 44^{\mathrm{lo}}\right)$ but not central $\left(\mathrm{CD} 62 \mathrm{~L}^{\text {hi }} \mathrm{CD} 44^{\mathrm{hi}}\right)$ nor effector memory $\left(\mathrm{CD} 62 \mathrm{~L}^{\text {lo }}\right.$ CD44 ${ }^{\text {hi }}$ ) $\mathrm{T}$ cells exhibited enhanced antidonor IFN- $\gamma$ responses 


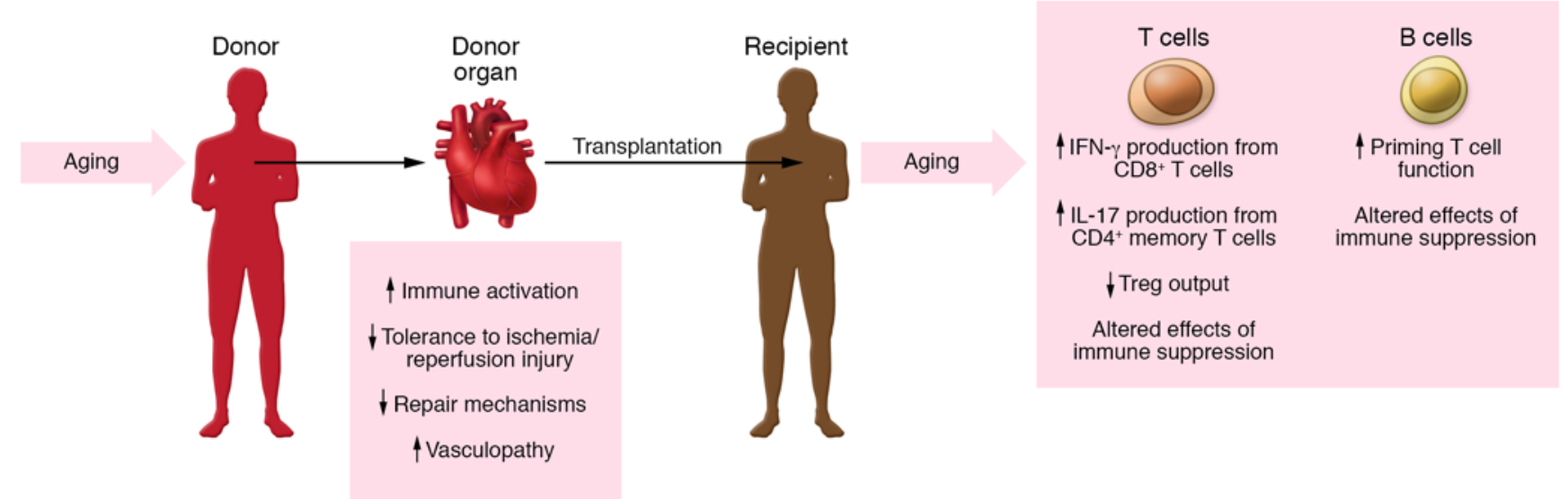

Figure 1. Impact of aging on donor organ and recipient immune system during organ transplantation. Aging increases the immunogenicity of the donor allograft, in part owing to passenger DCs. With aging, the donor graft has less tolerance in response to ischemia/reperfusion injury and likely has a reduced capacity to repair after implantation. Old grafts lead to increased transplant vasculopathy through unknown mechanisms. After transplantation, aging impairs CD8 ${ }^{+} \mathrm{T}$ cell responses to reject organ transplants, although $\mathrm{CD} 8^{+} \mathrm{T}$ cells may also impair immune modulation. CD4 ${ }^{+}$Th1 $\mathrm{T}$ cell responses are reduced but IL-17 production is increased with aging. Decreased Treg output from the thymus may impair transplantation tolerance in aged recipients. The aged B cell pool may enhance T cell alloreactive priming and may pose a barrier to immune modulation.

in aged mice (78). Functionally, the naive $\mathrm{CD}^{+} \mathrm{T}$ cells in this study did not exhibit features of memory $\mathrm{T}$ cells (i.e., rapid secretion of effector cytokines). A recent human study has identified a novel lineage of naive $\mathrm{CD}^{+} \mathrm{T}$ cells that exhibit memory-like features, which may be important for persistent viral infections (72). Whether the naive $\mathrm{CD}^{+} \mathrm{T}$ cells observed in the murine experimental transplant study are of a similar novel lineage to that reported in the human study will require further investigation.

Aging and B cell responses after transplantation. B cells exhibit intrinsic alterations such as impaired immunoglobulin class switching with aging that impair antibody responses to vaccination (82). $B$ cells produce alloreactive antibodies against the transplant, leading to acute and chronic rejection (83-85). However, until recently it was unknown how aging impacts B cell responses during organ transplantation. The B cell pool plays disparate roles depending on host age. In a skin allograft model in which anti-CD45Rb and antiCD154 enhance graft survival in young mice, B cell depletion led to a faster tempo to skin allograft rejection in young mice (86). In striking contrast, B cell depletion in aged mice (16-18 months of age) led to a 7-day delay in skin allograft survival (86). There was no alteration of regulatory B cell responses with aging; however, aged B cells exhibited enhanced priming of alloreactive B cells as compared with young B cells (86). A non-germinal zone, non-marginal zone B cell population, termed age-associated B cells (ABCs) (87), within the aged $\mathrm{B}$ cell pool were responsible for the enhanced $\mathrm{T}$ cell alloimmune priming and impaired the ability of anti-CD $45 \mathrm{Rb}$ and anti-CD154 to prolong skin allograft survival after adoptive transfer into young mice (86). Thus, this study indicates that ABCs within the aged host may represent a barrier to immune modulation and could indicate that B cell depletion, currently used in the treatment of antibody-mediated rejection, may have disparate effects depending on host age. Other aspects of how aging impacts antibody-mediated rejection are not yet known.

Impact of aging on immune suppression and transplant tolerance. As there is a reduced output of naturally occurring Tregs with thymic involution, there have been attempts to increase thymic size in aged recipients to expand Treg numbers in order to promote transplantation tolerance. In a murine heart transplant model, monotreatment with anti-CD45Rb induced long-term cardiac allograft acceptance in young mice (up to 150 days after transplantation). In contrast, recipient mice aged 14 months rejected their allografts before 60 days after transplantation (88). Either chemical or surgical castration increased thymic mass and Treg numbers. It also improved the efficacy of the protocol to prolong heart transplant survival over 100 days in the aged recipients (88). Thymic involution can be reversed in miniature swine by transplantation of thymi from swine aged 20 months into younger swine recipients (89). Retransplantation of these thymi into younger recipients allows acceptance of MHC class I-mismatched kidney transplants (89). However, increasing thymic size may not be sustainable and may not improve thymic function in the long term, as determined by a murine study (90) in which increasing thymic size via castration led to abnormal thymic architecture (90), suggesting that this approach could lead to aberrant thymic function and impaired central immune tolerance, a potential problematic issue in older patients prone to autoimmunity. However, not all studies have found that aged mice resist transplant tolerance of skin and cardiac allografts. In one study, mice 12 months of age were susceptible to transplantation tolerance after bone marrow transplantation and treatment with costimulatory blockade (91). Differences between this study and the one described above (88) may be due to tolerance regimen and differences between studies in the ages of the mice used $(88,91)$.

Commonly used immune suppressant medications for organ transplantation, like calcineurin inhibitors, have age-specific effects. Aged male C57BL/6 mice (18 months of age) treated with tacrolimus require only half the weight-adjusted dose to achieve trough levels found in young (2-3 months of age) murine skin recipients (46). These results are consistent with a prior prospective clinical study that found that recipients older than 65 years required half the body weight-adjusted dose to achieve therapeutic tacrolimus trough levels (92). $\mathrm{CD}^{+} \mathrm{T}$ cells isolated from the 
aged mice that had been treated with tacrolimus exhibited lower IFN- $\gamma$ and IL-2 secretion but a higher level of IL-10 compared with young animals (46). This finding indicates that aging of recipients may fundamentally alter the immunological functions of immune suppression, in addition to the altered pharmacokinetics, specifically the age-related decline of hepatic cytochrome P450 (93). Clearly, future clinical studies will be needed to determine whether age-adjusted immune suppression enhances the efficacy of organ transplantation in older recipients.

\section{Conclusions}

Aging has broad and complex effects on both the immune system and organ function (Figure 1). Given the rise in the number of older people receiving organ transplants, how aging impacts both the donor allograft and the recipient immune system is poorly understood in contrast to other areas in the transplant field. Clinically, older organs elicit a more potent immune response that leads to a faster tempo of acute graft rejection with increased vasculopathy. Older transplant recipients exhibit reduced frequency of acute allograft rejection but an increased prevalence of infections and malignancies due to the consequences of immunosenescence. Functional alterations in both recipient $\mathrm{T}$ and $\mathrm{B}$ cell populations may slow the tempo of acute allograft rejection in older recipients, but these populations of immune cells may also hinder the induction of transplant tolerance. Many unanswered questions remain, including how aging impacts transplant vasculopathy, how it affects the innate immune system to alter IRI, and how it influences transplantation tolerance. These are just some areas that need to be investigated in the future. Increasing our fundamental knowledge of how aging is involved in the immune response to organ transplantation can ultimately lead to age-specific therapies to improve health outcomes for older transplant recipients.

\section{Acknowledgments}

DRG is supported by NIH award AG028082, R01HL130669, and R01HL127687 and National Institute on Aging leadership award AG050096.

Address correspondence to: Daniel R. Goldstein, NCRC B26207N, 2800 Plymouth Road, Ann Arbor, Michigan 48109, USA. Phone: 734.936.1407; E-mail: drgoldst@med.umich.edu.
1. United Nations. Executive summary. In: World Population Prospects: The 2010 Revision. Vol. 1: Comprehensive Tables. New York, New York, USA: United Nations; 2010:xv. http://www. un.org/en/development/desa/population/ publications/pdf/trends/WPP2010/WPP2010_ Volume-I_Comprehensive-Tables.pdf.

2. Hertz MI, et al. Scientific Registry of the International Society for Heart and Lung Transplantation: introduction to the 2011 annual reports. J Heart Lung Transplant. 2011;30(10):1071-1077.

3. de Fijter JW. The impact of age on rejection in kidney transplantation. Drugs Aging. 2005;22(5):433-449.

4. Flechner SM. Will you still list me when I'm 64? Apologies to Lennon and McCartney. JAm Geriatr Soc. 2002;50(1):195-197.

5. Crespo-Leiro MG, et al. Morbidity and mortality among heart transplant patients older and younger than 65 years. Transplant Proc. 1999;31(6):2537-2538.

6. Cameron JS. Renal transplantation in the elderly. Int Urol Nephrol. 2000;32(2):193-201.

7. Blanche $\mathrm{C}$, et al. Heart transplantation in patients seventy years of age and older: a comparative analysis of outcome. J Thorac Cardiovasc Surg. 2001;121(3):532-541.

8. de Bruin AM, Libregts SF, Valkhof M, Boon L, Touw IP, Nolte MA. IFN $\gamma$ induces monopoiesis and inhibits neutrophil development during inflammation. Blood. 2012;119(6):1543-1554.

9. Meier-Kriesche HU, et al. Increased immunosuppressive vulnerability in elderly renal transplant recipients. Transplantation. 2000;69(5):885-889.

10. Demers P, Moffatt S, Oyer PE, Hunt SA, Reitz BA, Robbins RC. Long-term results of heart transplantation in patients older than 60 years. J Thorac Cardiovasc Surg. 2003;126(1):224-231.

11. Renlund DG, et al. Age-associated decline in cardiac allograft rejection. Am JMed.
1987;83(3):391-398.

12. Snell GI, De Hoyos A, Winton T, Maurer JR. Lung transplantation in patients over the age of 50 . Transplantation. 1993;55(3):562-566.

13. Bradley BA. Rejection and recipient age. Transpl Immunol. 2002;10(2-3):125-132.

14. Pirsch JD, et al. Cadaveric renal transplantation with cyclosporine in patients more than 60 years of age. Transplantation. 1989;47(2):259-261.

15. Du W, et al. Age-associated vascular inflammation promotes monocytosis during atherogenesis. Aging Cell. 2016;15(4):766-777.

16. Tsukamoto H, Huston GE, Dibble J, Duso DK, Swain SL. Bim dictates naive CD4 T cell lifespan and the development of age-associated functional defects. JImmunol. 2010;185(8):4535-4544.

17. Poulose N, Raju R. Aging and injury: alterations in cellular energetics and organ function. Aging Dis. 2014;5(2):101-108.

18. Oberhuber R, et al. CD11 $\mathrm{c}^{+}$dendritic cells accelerate the rejection of older cardiac transplants via interleukin-17A. Circulation. 2015;132(2):122-131.

19. Kasiske BL. The influence of donor age on renal function in transplant recipients. Am J Kidney Dis. 1988;11(3):248-253.

20. Hariharan S, McBride MA, Bennett LE, Cohen EP. Risk factors for renal allograft survival from older cadaver donors. Transplantation. 1997;64(12):1748-1754.

21. Del Rizzo DF, et al. The role of donor age and ischemic time on survival following orthotopic heart transplantation. J Heart Lung Transplant. 1999;18(4):310-319.

22. Dreyer GJ, Hemke AC, Reinders ME, de Fijter JW. Transplanting the elderly: Balancing aging with histocompatibility. Transplant Rev (Orlando). 2015;29(4):205-211.

23. Tan RY, Allen JC Jr, Kee T, Jafar TH. Predictors of low estimated glomerular filtration rate after living kidney donation in a Southeast Asian popula- tion from Singapore [published online ahead of print June 28, 2016]. Nephrology (Carlton). https://doi.org/10.1111/nep.12845.

24. Chau EM, et al. Increased incidence of chronotropic incompetence in older donor hearts. J Heart Lung Transplant. 1995;14(4):743-748.

25. Loebe M, Potapov EV, Hummel M, Weng Y, Bocksch W, Hetzer R. Medium-term results of heart transplantation using older donor organs. J Heart Lung Transplant. 2000;19(10):957-963.

26. De Perrot $\mathrm{M}$, et al. Impact of donors aged 60 years or more on outcome after lung transplantation: results of an 11-year singlecenter experience. J Thorac Cardiovasc Surg. 2007;133(2):525-531.

27. Frei U, et al. Prospective age-matching in elderly kidney transplant recipients - a 5-year analysis of the Eurotransplant Senior Program. Am J Transplant. 2008;8(1):50-57.

28. Bahde R, et al. Prognostic factors for kidney allograft survival in the Eurotransplant Senior Program. Ann Transplant. 2014;19:201-209.

29. Tullius SG, Milford E. Kidney allocation and the aging immune response. $N$ Engl J Med. 2011;364(14):1369-1370.

30. Yi T, et al. Reperfusion injury intensifies the adaptive human $\mathrm{T}$ cell alloresponse in a humanmouse chimeric artery model. Arterioscler Thromb Vasc Biol. 2012;32(2):353-360.

31. Chen GY, Nuñez G. Sterile inflammation: sensing and reacting to damage. Nat Rev Immunol. 2010;10(12):826-837.

32. Shen H, Kreisel D, Goldstein DR. Processes of sterile inflammation. JImmunol. 2013;191(6):2857-2863.

33. Wu H, Chadban SJ. Roles of Toll-like receptors in transplantation. Curr Opin Organ Transplant. 2014;19(1):1-7.

34. Wu H, et al. Absence of MyD88 signaling induces donor-specific kidney allograft tolerance. JAm Soc Nephrol. 2012;23(10):1701-1716. 
35. Braza F, Brouard S, Chadban S, Goldstein DR. Role of TLRs and DAMPs in allograft inflammation and transplant outcomes. Nat Rev Nephrol. 2016;12(5):281-290.

36. Shaw AC, Goldstein DR, Montgomery RR. Agedependent dysregulation of innate immunity. Nat Rev Immunol. 2013;13(12):875-887.

37. Puntmann VO, Taylor PC, Mayr M. Coupling vascular and myocardial inflammatory injury into a common phenotype of cardiovascular dysfunction: systemic inflammation and aging - a minireview. Gerontology. 2011;57(4):295-303.

38. Csiszar A, Sosnowska D, Wang M, Lakatta EG, Sonntag WE, Ungvari Z. Age-associated proinflammatory secretory phenotype in vascular smooth muscle cells from the non-human primate Macaca mulatta: reversal by resveratrol treatment. J Gerontol A Biol Sci Med Sci. 2012;67(8):811-820.

39. Michaud M, et al. Proinflammatory cytokines, aging, and age-related diseases. JAm Med Dir Assoc. 2013;14(12):877-882.

40. Song Y, Shen H, Schenten D, Shan P, Lee PJ, Goldstein DR. Aging enhances the basal production of IL- 6 and CCL2 in vascular smooth muscle cells. Arterioscler Thromb Vasc Biol. 2012;32(1):103-109.

41. Lucas DT, Szweda LI. Cardiac reperfusion injury: aging, lipid peroxidation, and mitochondrial dysfunction. Proc Natl Acad Sci US A. 1998;95(2):510-514.

42. Bugger $\mathrm{H}$, Witt CN, Bode C. Mitochondrial sirtuins in the heart. Heart Failure Reviews. 2016;21(5):519-528.

43. Gomes AP, et al. Declining NAD (+) induces a pseudohypoxic state disrupting nuclearmitochondrial communication during aging. Cell. 2013;155(7):1624-1638.

44. Gu C, et al. Impaired cardiac SIRT1 activity by carbonyl stress contributes to aging-related ischemic intolerance. PLoS One. 2013;8(9):e74050.

45. Okaya T, et al. Age-dependent responses to hepatic ischemia/reperfusion injury. Shock. 2005;24(5):421-427.

46. Krenzien F, et al. Age-dependent metabolic and immunosuppressive effects of tacrolimus [published online ahead of print October 18, 2016]. Am J Transplant. https://doi.org/ 10.1111/ajt.14087.

47. Ordemann R, et al. Enhanced allostimulatory activity of host antigen-presenting cells in old mice intensifies acute graft-versus-host disease. JClin Invest. 2002;109(9):1249-1256.

48. Guilliams M, et al. Alveolar macrophages develop from fetal monocytes that differentiate into longlived cells in the first week of life via GM-CSF. JExp Med. 2013;210(10):1977-1992.

49. Hashimoto D, et al. Tissue-resident macrophages self-maintain locally throughout adult life with minimal contribution from circulating monocytes. Immunity. 2013;38(4):792-804.

50. Abadja F, Sarraj B, Ansari MJ. Significance of T helper 17 immunity in transplantation. Curr Opin Organ Transplant. 2012;17(1):8-14.

51. Keller MR, Burlingham WJ. Loss of tolerance to self after transplant. Semin Immunopathol. 2011;33(2):105-110.

52. Shen H, Tesar BM, Du W, Goldstein DR. Aging impairs recipient $\mathrm{T}$ cell intrinsic and extrinsic factors in response to transplantation. PLoS One. 2009;4(1):e4097.

53. Nagji AS, et al. Donor age is associated with chronic allograft vasculopathy after adult heart transplantation: implications for donor allocation. Ann Thorac Surg. 2010;90(1):168-175.

54. Gao HZ, Hunt SA, Alderman EL, Liang D, Yeung AC, Schroeder JS. Relation of donor age and preexisting coronary artery disease on angiography and intracoronary ultrasound to later development of accelerated allograft coronary artery disease. J Am Coll Cardiol. 1997;29(3):623-629.

55. Roig E, et al. Heart transplantation using allografts from older donors: Multicenter study results. J Heart Lung Transplant. 2015;34(6):790-796.

56. Chih S, Chong AY, Mielniczuk LM, Bhatt DL, Beanlands RS. Allograft vasculopathy: the Achilles' heel of heart transplantation. J Am Coll Cardiol. 2016;68(1):80-91.

57. Tullius SG, et al. Contribution of prolonged ischemia and donor age to chronic renal allograft dysfunction. J Am Soc Nephrol. 2000;11(7):1317-1324.

58. Wang M, et al. Proinflammatory profile within the grossly normal aged human aortic wall. Hypertension. 2007;50(1):219-227.

59. Wang M, Jiang L, Monticone RE, Lakatta EG. Proinflammation: the key to arterial aging. Trends Endocrinol Metab. 2014;25(2):72-79.

60. Yung R. Changes in immune function with age. Rheum Dis Clin N Am. 2000;26(3):455-473.

61. Linton PJ, Dorshkind K. Age-related changes in lymphocyte development and function. Nat Immunol. 2004;5(2):133-139.

62. Haynes L, Linton PJ, Eaton SM, Tonkonogy SL, Swain SL. Interleukin 2, but not other common gamma chain-binding cytokines, can reverse the defect in generation of CD4 effector T cells from naive T cells of aged mice. J Exp Med. 1999;190(7):1013-1024.

63. Thoman ML, Weigle WO. Cell-mediated immunity in aged mice: an underlying lesion in IL 2 synthesis. J Immunol. 1982;128(5):2358-2361.

64. Tesar BM, et al. Murine [corrected] myeloid dendritic cell-dependent toll-like receptor immunity is preserved with aging. Aging Cell. 2006;5(6):473-486.

65. Boucher N, Dufeu-Duchesne T, Vicaut E, Farge D, Effros RB, Schächter F. CD28 expression in $\mathrm{T}$ cell aging and human longevity. Exp Gerontol. 1998;33(3):267-282.

66. Garcia GG, Miller RA. Single-cell analyses reveal two defects in peptide-specific activation of naive $\mathrm{T}$ cells from aged mice. J Immunol. 2001;166(5):3151-3157.

67. Nishioka T, Shimizu J, Iida R, Yamazaki S, Sakaguchi S. CD $4^{+} \mathrm{CD} 25^{+} \mathrm{Foxp}^{+} \mathrm{T}$ cells and $\mathrm{CD} 4^{+} \mathrm{CD} 25^{-}{ }^{-}{ }^{-}{ }^{+} \mathrm{T}$ cells in aged mice. J Immunol. 2006;176(11):6586-6593.

68. Gregg R, et al. The number of human peripheral blood $\mathrm{CD} 4{ }^{+} \mathrm{CD} 25$ high regulatory $\mathrm{T}$ cells increases with age. Clin Exp Immunol. 2005;140(3):540-546.

69. Sharma S, Dominguez AL, Lustgarten J. High accumulation of $\mathrm{T}$ regulatory cells prevents the activation of immune responses in aged animals. JImmunol. 2006;177(12):8348-8355.
70. Zhang X, Fujii H, Kishimoto H, LeRoy E, Surh $\mathrm{CD}$, Sprent J. Aging leads to disturbed homeostasis of memory phenotype CD8(+) cells. J Exp Med.2002;195(3):283-293.

71. Haynes L, Eaton SM, Burns EM, Randall TD, Swain SL. CD4 T cell memory derived from young naive cells functions well into old age, but memory generated from aged naive cells functions poorly. Proc Natl Acad Sci U S A. 2003;100(25):15053-15058.

72. Pulko V, et al. Human memory T cells with a naive phenotype accumulate with aging and respond to persistent viruses. Nat Immunol. 2016;17(8):966-975.

73. Kasiske BL, Snyder JJ, Gilbertson DT, Wang C Cancer after kidney transplantation in the United States. Am J Transplant. 2004;4(6):905-913.

74. Engels EA, et al. Spectrum of cancer risk among US solid organ transplant recipients. JAMA. 2011;306(17):1891-1901.

75. Meier-Kriesche HU, Ojo AO, Hanson JA, Kaplan B. Exponentially increased risk of infectious death in older renal transplant recipients. Kidney Int. 2001;59(4):1539-1543.

76. Tesar BM, Du W, Shirali AC, Walker WE, Shen H, Goldstein DR. Aging augments IL-17 T-cell alloimmune responses. Am J Transplant. 2009;9(1):54-63.

77. Denecke C, et al. Prolonged graft survival in older recipient mice is determined by impaired effector T-cell but intact regulatory T-cell responses. PLoS One. 2010;5(2):e9232.

78. Du W, Shen H, Galan A, Goldstein DR. An agespecific CD8+ T cell pathway that impairs the effectiveness of strategies to prolong allograft survival. J Immunol. 2011;187(7):3631-3640.

79. Bedi DS, et al. Defective CD8 Signaling Pathways Delay Rejection in Older Recipients. Transplantation. 2016;100(1):69-79.

80. Kim JI, et al. Elevated levels of interferon- $\gamma$ production by memory $\mathrm{T}$ cells do not promote transplant tolerance resistance in aged recipients. PLoS One. 2013;8(12):e82856.

81. Adams AB, et al. Heterologous immunity provides a potent barrier to transplantation tolerance. J Clin Invest. 2003;111(12):1887-1895.

82. Frasca D, Blomberg BB. B cell function and influenza vaccine responses in healthy aging and disease. Curr Opin Immunol. 2014;29:112-118.

83. Pankewycz O, Soliman K, Laftavi MR. The increasing clinical importance of alloantibodies in kidney transplantation. Immunol Invest. 2014;43(8):775-789.

84. Dalloul A. B-cell-mediated strategies to fight chronic allograft rejection. Front Immunol. 2013;4:444.

85. Tse GH, et al. Intrarenal B cell cytokines promote transplant fibrosis and tubular atrophy. Am J Transplant. 2015;15(12):3067-3080.

86. Mori DN, Shen H, Galan A, Goldstein DR. Aged $B$ cells alter immune regulation of allografts in mice. Eur J Immunol. 2016;46(11):2650-2658.

87. Hao Y, O'Neill P, Naradikian MS, Scholz JL, Cancro MP. A B-cell subset uniquely responsive to innate stimuli accumulates in aged mice. Blood. 2011;118(5):1294-1304

88. Zhao G, et al. Inhibition of transplantation tolerance by immune senescence is reversed 
by endocrine modulation. Sci Transl Med. 2011;3(87):87ra52.

89. Nobori S, et al. Thymic rejuvenation and the induction of tolerance by adult thymic grafts. Proc Natl Acad Sci U S A. 2006;103(50):19081-19086.

90. Griffith AV, Fallahi M, Venables T, Petrie HT.

Persistent degenerative changes in thymic organ function revealed by an inducible model of organ regrowth. Aging Cell. 2012;11(1):169-177.

91. Hock K, Oberhuber R, Lee YL, Wrba F, Wekerle

$\mathrm{T}$, Tullius SG. Immunosenescence does not

abrogate engraftment of murine allogeneic bone

marrow. Transplantation. 2013;95(12):1431-1438.

92. Jacobson PA, et al. Lower calcineurin inhibitor doses in older compared to younger kidney transplant recipients yield similar troughs. Am J Transplant. 2012;12(12):3326-3336.

93. Warrington JS, Greenblatt DJ, von Moltke LL. Age-related differences in CYP3A expression and activity in the rat liver, intestine, and kidney. JPharmacol Exp Ther. 2004;309(2):720-729. 